\title{
AS CONTRIBUIÇÕES DA TERAPIA COGNITIVO-COMPORTAMENTAL NO MANEJO DO SUICÍDIO
}

\author{
Amanda Caroline Silva Freitas ${ }^{1}$ \\ Arthur Siqueira de Sene ${ }^{2}$
}

\section{RESUMO}

INTRODUÇÃO: É evidente que a sociedade tem passado por transformações profundas na sua compreensão de mundo o que consequentemente atua, uma das formas de apresentação da dificuldade e sofrimento envolvidos no estabelecimento das inter-relações do indivíduo são as tentativas de suicídio. Os casos de suicídio tornaram-se um problema de saúde pública em decorrência do aumento significativo de casos a nível mundial sendo o suicídio referente a muito mais que o ato de matar a si mesmo, o comportamento suicida envolve: ideação, planejamento, tentativa e suicídio, ou seja, não se trata de um ato aleatório ou sem finalidade, mas representa para quem o faz uma saída para um problema o qual está lhe causando sofrimento. OBJETIVO: Mostrar que a Terapia Cognitivo Comportamental (TCC) se tem mostrado efetiva na prevenção e tratamento do suicídio, reduzindo sintomas e taxas de recorrência. MÉTODO: O presente trabalho pretende avaliar, por meio de uma revisão da literatura, as contribuições da TCC no manejo do suicídio. Para a realização da revisão narrativa da literatura com a seleção de artigos completos disponíveis eletronicamente, compreendidos no período de 2006-2017. RESULTADOS: Constatou que o suicídio representa um problema de saúde pública a nível mundial, complexo, multidimensional, com grande impacto econômico e social; porém evitável. Levantamentos recentes demonstram o Sudeste Asiático como a região com índices mais altos de suicídios; apesar de ter um coeficiente considerado baixo, foram 11.821 mortes no último levantamento global realizado em 2012. Observa-se na literatura existente a alta incidência de suicídio associada a transtornos psiquiátricos, estima-se que apenas $10 \%$ dos indivíduos que comentem suicídio

\footnotetext{
${ }^{1}$ Acadêmica do curso de psicologia da Faculdade Patos de Minas - FPM. E-mail de contato: amandafreitaspsicologia@gmail.com

${ }^{2}$ Docente do departamento de psicologia da Faculdade Patos de Minas - FPM. E-mail de contato:

arthurssene@gmail.com
} 
não tenham uma patologia psiquiátrica, ao que se refere aos fatores sociodemográficos, o suicídio mantém-se predominantemente no sexo masculino, crescendo sua prática entre os jovens. Há que observar, a presença de tentativas anteriores de suicídio, indivíduos com este histórico tem de 38 a 40 vezes mais chances de morrerem por suicídio do que o esperado, as pesquisas apontam que estas pessoas apresentam perturbações psiquiátricas mais severas do que tentadores únicos. Sabe-se também que indivíduos com impulsividade, agressividade, desesperança, perfeccionismo e dificuldades na relação de problemas estão mais abertos a ideação suicida. CONSIDERAÇÕES FINAIS: Dada à importância do assunto, torna-se necessário o desenvolvimento de políticas públicas direcionadas a prevenção e tratamento do suicídio, por tratar-se de assunto silenciado, camuflado, pouco discutido e tratado de forma velada. O crescente aumento dos índices de suicídio demonstra que este fenômeno deve ser alvo de ações especificas dos setores público e privado, ligados ou não aos serviços de saúde mental. Tais ações devem ser direcionadas a reduzir e/ou minimizar os fatores predisponentes e precipitantes relacionados a ideação suicida, além de detectar precocemente comportamentos suicidas. Aponta-se a necessidade da realização de estudos e pesquisas sobre a terapia cognitivo comportamental e suicídio, há uma quantidade limitada de estudos que abordam esta temática, sendo indispensável o desenvolvimento de estudos que comprovem a eficácia das técnicas utilizadas no manejo do suicídio.

Palavras-chave: Suicídio; Terapia Cognitivo Comportamental; Tratamento. 